\title{
Investigation on Relationship between Test Anxiety and Academic Performance of Nursing and Midwifery Students in Tabriz and Maragheh-Iran
}

\author{
Maedeh Alizadeh', Fattaneh Karimi', Sousan Valizadeh², Mohammad Asghari Jafarabadi³, \\ Parvin Cheraghi ${ }^{1}$, Asghar Tanomand ${ }^{*}$ \\ ${ }^{1}$ Maragheh Faculty of Medical Sciences, Tabriz University of Medical Sciences, Tabriz, Iran \\ ${ }^{2}$ Faculty of Nursing and Midwifery, Tabriz University of Medical Sciences, Tabriz, Iran \\ ${ }^{3}$ Road Traffic Injury Research Center, Tabriz University of Medical Sciences, Tabriz, Iran \\ Email: "tanomanda@yahoo.com
}

Received 19 October 2014; revised 5 December 2014; accepted 20 December 2014

Copyright (C) 2014 by authors and Scientific Research Publishing Inc.

This work is licensed under the Creative Commons Attribution International License (CC BY).

http://creativecommons.org/licenses/by/4.0/

(c) (i) Open Access

\begin{abstract}
Background and Aim: Given the dramatic decline in the ability of test due to test anxiety, the goal of this study was to evaluate the relationship between test anxiety and academic performances in students. Materials and Methods: This descriptive-analytical study was performed on 216 Iranian nursing and midwifery students in 2011-2012, utilizing Sarason Anxiety Inventory, demographic checklist and the average mark of students in the period of midterm and final exam. Multinomial logistic regression analyses by reporting odds ratios and their $95 \%$ confidence intervals were performed by SPSS17 software to assess the relationship between test anxiety and academic performances. Results: Mild, moderate and sever test anxiety was observed in 30.6, 43.1 and 26.4 percent of students respectively. Test anxiety was significantly related to academic performance (average), major and city. Also, there was $52.9 \%$ decrease for odds of having sever anxiety (compared to mild anxiety) with 1 point increase in average $(\mathrm{OR}=0.471,95 \% \mathrm{CI}=(0.298-0.745)$ and $\mathrm{p}$ $=0.001)$. Conclusions: Due to inverse relationship between test anxiety and academic performance, performing preventive programs such as in time treatment of anxiety, empowering the students to deal with anxiety and conducting consulting services for how to studying are very important. Consequently it would be a big step in decreasing the test anxiety and therefore in improving the academic performance.
\end{abstract}

${ }^{*}$ Corresponding author.

How to cite this paper: Alizadeh, M., Karimi, F., Valizadeh, S., Jafarabadi, M.A., Cheraghi, P. and Tanomand, A. (2014) Investigation on Relationship between Test Anxiety and Academic Performance of Nursing and Midwifery Students in Tabriz and Maragheh-Iran. Health, 6, 3055-3061. http://dx.doi.org/10.4236/health.2014.621345 


\section{Keywords}

\section{Test Anxiety, Academic Performance, Nursing, Midwifery, Students}

\section{Introduction}

Anxiety is a part of every human life in all societies and is regarded as a suitable response. Balanced and constructive level of anxiety makes us do things timely and appropriately and have durable life.

On the other hand, there is morbid anxiety which is considered as a source of failures and lack of compromise and includes a range of both cognitive, physical disorders and unjustified fears and panic, so that the person is deprived of the possibility of a major part of the features [1]-[4].

Test anxiety is a common type of performance anxiety that 10 to 20 percent of students suffer from it. That is a kind of anxiety or social phobia which makes person doubt about his ability and it results in reduction of power to deal with test situations. So the person, who suffers from test anxiety, knows the answer, but anxiety prevents him from using his knowledge as a result; it is expected that there is an inverse relationship between anxiety scores and test scores [5].

Sarason and Mandler believed that in a test position, test-related information and learned anxiety cases come into practice. Some of anxiety cases are associated with tests in question and others are not associated with them.

Therefore, if motivated anxiety is associated with the test content, efficiency levels are increased; otherwise the level of efficiency is refused [1].

Also, Sarason realized that anxiety, as a form of employment, is identified with individual minimization, makes one doubt about his abilities and often leads to negative cognitive evaluation, decentralization, adverse physiological reactions and decline in academic performance. As a result, there is a significant inverse relationship between anxiety scores and scores of test [6] [7].

Test anxiety, as a common and important educational phenomenon, has a close relationship with educational performance and academic achievement. In some studies, this association was observed with less intensity and in one study no significant relationship was observed [8].

A research by the title of "test anxiety reasons in students" by Narimani et al. showed that between male and female students, there are significant differences in test anxiety ([7] [9] and [10]).

The researchers estimated each year about ten million high school students and 15 percent of university students in America are experiencing test anxiety [11].

In Iran, also afraid of getting poor grades and blame by family, ridicule by classmates and friends, fear of inability to continue studying, always puts the students about psychological harassment [12].

Experience of researchers shows that majority of the students ask about test anxiety and controlling it. On the other hand no research has been conducted for studying test anxiety in these faculties, plus the results of studies conducted in other national studies [12]; confirming test anxiety and its adverse effects on academic performance shows the necessity of this study.

This research with the aim of studying relationship between test anxiety and academic performance of nursing and midwifery students in Maragheh and Tabriz (west of Iran) was conducted.

\section{Material and Method}

This descriptive-analytical study was performed on 216 students of the Maragheh and Tabriz nursing and midwifery faculty in 2011-2012. Course of students includes nursing, midwifery, medical emergency and health. Preliminary study including 30 samples for assessment of relationship between test anxiety and academic performance $(\mathrm{OR}=0 / 568)$ was conducted. Considering the amount of confidence level $95 \%$, power of test $90 \%$, two series of tests and using the software of G-Power, sample size was obtained 216 cases.

Simple random sampling was performed based on the available list in the education department of faculties so that samples selected randomly. In case if students had satisfaction, they have been participated in the study and if any student was not willing to do the study, another one randomly was selected. The data collection instrument included a Sarason 37-item questionnaire test anxiety [3], demographic characteristics checklist and the 
average mark of students. Questionnaires completed by students in the interval between examinations of midterm and end of the term.

Cronbach's alpha coefficient which was used to check the reliability of the data in this study was approved 0.746 .

For accounting scale score Sarason test anxiety items 3, 15, 26, 27, 29 and 33 take incorrect responses and other items take correct responses. For calculating anxiety score first in the same direction with the correct responses and then incorrect responses are coded inversely then anxiety score is obtained by adding new items to each other. Accordingly, the scope of possible test anxiety score becomes $(0-37)$. Scores less than or equal 12 , 12.1 - 20 and higher than 20.1, respectively, show mild, moderate and intensive anxiety [3]. According to the available checklist, variables in demographic information include age, city of school location, sex, marital status, course, year of entry to the university. In addition current term average and past terms average obtained by referring to the educational department of faculties. Participants in this study are assured that personal information is kept confidential and their information is just used for study.

\section{Statistical Analysis}

Data of qualitative and quantitative variables, respectively, mean (SD) and frequency (percent) was reported. For studying the relationship between the variables: city (Maragheh-Tabriz), sex (female-male), marital status (single-married), course (nursing-midwifery-medical emergency, health), years of enter to university, age and average scours variables with test anxiety, in the form of a one-variable and multivariable, multi nominal logistic regression analysis was used (with considering three state anxiety conditions). Odds ratio (OR) index and it's 95\% confidence interval of both unadjusted (one-variable analysis) and adjusted (multivariate analysis) was evaluated as a measure of its effect. Software (SPSS17) is used for data analysis and for all analyses $p<0.05$ is considered as significant.

\section{Results}

157 students (72.7\%) out of 216 participants in the study were female and 59 (27.3\%) male and mean age of students 21/58 with a standard deviation of 2/95. Mean average was 17.05 with standard deviation 1.15 and mean test anxiety score of 15.65 with standard deviation, 5/94 was obtained. Based on study test anxiety results of $30.5 \%$ of students were mild, $43.1 \%$ moderate and $26.4 \%$ sever level (Table 1 ).

Based on one-variable analysis, city, the current semester score and course of study variables showed significant relationship with test anxiety (for all three variables $\mathrm{p}<0.05$ ). In this analysis it was observed that students of Maragheh compare with students of Tabriz had lower anxiety level ( $\mathrm{OR}=0.272$ and $\mathrm{OR}=0.137$ respectively for moderate and sever level of anxiety compared with the reference category). Also level of student's anxiety decreased with increasing current semester average score $(\mathrm{OR}=0.546$ for high level of anxiety compared with the reference category of mild anxiety). In addition nursing courses ( $\mathrm{OR}=0.090$ for high anxiety compared with the reference category, mild anxiety), medical emergency ( $\mathrm{OR}=0.083$ for high anxiety compared with the reference category, mild anxiety) and health ( $\mathrm{OR}=0.125$ and $\mathrm{OR}=0.083$ respectively, for medium and high levels of anxiety compared with the reference category, mild anxiety), had lower anxiety level compared with the field of midwifery (Table 2).

In this study significant variables candidate for entry into multivariable analysis and studied for relationship of these variables with test anxiety (Table 3). Based on multivariable analysis, city and current semester score variables showed significant relationship with test anxiety ( $p<0.05$ for both variables) and there was no significant relationship between course of study and test anxiety ( $\mathrm{p}>0.05)$.

In this analysis it was observed that the students of Maragha compare with students of Tabriz had lower test anxiety level (OR $=0.178$ to high level of anxiety compare with mild anxiety as the reference category).

Also students test anxiety level decreased with increased the current semester score (OR $=0.471$ to high level of anxiety compare with mild anxiety as the reference category). In addition health course automatically excluded by software due to lack of samples (Table 3).

\section{Discussion}

Test anxiety is a serious problem for many students it has been described as the most powerful obstacle to 
Table 1. Abstract indexes for demographic characteristic of persons attended in the study.

\begin{tabular}{|c|c|c|}
\hline Variables & Frequent & Percent \\
\hline \multicolumn{3}{|l|}{ City: } \\
\hline Maragheh & 161 & 74.5 \\
\hline Tabriz & 55 & 25.5 \\
\hline \multicolumn{3}{|l|}{ Sex: } \\
\hline Female & 157 & 72.7 \\
\hline Male & 59 & 27.3 \\
\hline \multicolumn{3}{|l|}{ Marital status: } \\
\hline Single & 169 & 79.0 \\
\hline Married & 45 & 21.0 \\
\hline \multicolumn{3}{|l|}{ Course of study: } \\
\hline Nursing & 121 & 56.0 \\
\hline Medical emergency & 47 & 21.8 \\
\hline Health & 19 & 8.8 \\
\hline Midwifery & 29 & 13.4 \\
\hline \multicolumn{3}{|l|}{ Year of entry to the university: } \\
\hline 2011 & 84 & 38.9 \\
\hline 2010 & 88 & 40.7 \\
\hline 2009 & 6 & 2.8 \\
\hline 2008 & 14 & 6.5 \\
\hline 2007 & 24 & 11.1 \\
\hline \multicolumn{3}{|l|}{ Sarason anxiety: } \\
\hline Mild & 66 & 30.6 \\
\hline Moderate & 93 & 43.1 \\
\hline Severe & 57 & 26.4 \\
\hline Age $^{\#}$ & & $21.58(2.95)$ \\
\hline 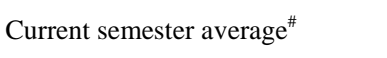 & & $17.06(1.15)$ \\
\hline Mean of past semesters average $e^{\#}$ & & $16.69(1.17)$ \\
\hline Sarason anxiety score ${ }^{\#}$ & & $15.66(5.94)$ \\
\hline
\end{tabular}

\#: Mean and standard deviation (SD) of variables are reported.

learning in an educational setting [10]. Hambree [13] stated that it has been linked to fear of negative evaluation, dislike of testing and less effective study skills and has been identified as one of the factors that impair academic performance.

The effect of test anxiety on academic performance has been thoroughly investigated by many researchers [14]. Generally, the study of the relationship between test anxiety and academic achievement began in the early 1900's [11]. The comprehensive reviews by Hambree [13] studies showed that test anxiety caused poor performance. It implied that test anxiety had a negative relation with student's performance. Therefore, the high-test anxious students tended to score lower than low-test anxious students. This result was supported by the findings of various studies [10].

A review of current literature shows that test anxiety is a dynamic, progressive and sometimes controversial area for students. Hembree's [13] research findings suggest that test anxiety is a key factor in undermining student's academic performance. Chapell, Benjamin, Michael, Masami, Brian, Aaron et al. [15] investigated relationship between test anxiety and academic performance of the undergraduate and graduate students and found a significant but small in-verse relationship between test anxiety and grade point average in both groups. The 
Table 2. Results of one-variable analyses of multinomial regression for studying relationship between on question variables and test anxiety.

\begin{tabular}{|c|c|c|c|c|c|c|c|c|}
\hline \multirow{3}{*}{ Variables } & \multicolumn{4}{|c|}{ Medium level anxiety compared with mild level } & \multicolumn{4}{|c|}{ High level anxiety compared with mild level } \\
\hline & \multirow{2}{*}{ OR } & \multicolumn{2}{|c|}{ 95\% confidence interval OR } & \multirow{2}{*}{ p-Value } & \multirow{2}{*}{ OR } & \multicolumn{2}{|c|}{ 95\% confidence interval OR } & \multirow{2}{*}{ p-Value } \\
\hline & & Low level & High level & & & Low level & High level & \\
\hline \multicolumn{9}{|l|}{ City } \\
\hline Tabriz & Reference category & - & - & - & Reference category & - & - & - \\
\hline Maragheh & 0.272 & 0.105 & 0.708 & 0.008 & 0.137 & 0.051 & 0.370 & $<0.001$ \\
\hline \multicolumn{9}{|l|}{ Sex } \\
\hline Male & Reference category & - & - & - & Reference category & - & - & - \\
\hline Female & 0.988 & 0.493 & 1.982 & 0.973 & 1.368 & 0.605 & 3.096 & 0.452 \\
\hline Age & 1.022 & 0.907 & 1.152 & 0.721 & 1.078 & 0.953 & 1.219 & 0.234 \\
\hline \multicolumn{9}{|l|}{ Marital status } \\
\hline Single & Reference category & - & - & - & Reference category & - & - & - \\
\hline Married & 0.811 & 0.365 & 1.801 & 0.607 & 0.718 & 0.297 & 1.735 & 0.462 \\
\hline $\begin{array}{l}\text { Current semester } \\
\text { average }\end{array}$ & 0.831 & 0.587 & 1.176 & 0.295 & 0.546 & 0.362 & 0.823 & 0.004 \\
\hline $\begin{array}{c}\text { Mean of past } \\
\text { semesters average }\end{array}$ & 0.964 & 0.649 & 1.432 & 0.855 & 0.837 & 0.541 & 1.295 & 0.424 \\
\hline \multicolumn{9}{|l|}{ Course of study } \\
\hline Midwifery & Reference category & - & - & - & Reference category & - & - & - \\
\hline Nursing & 0.225 & 0.048 & 1.062 & 0.060 & 0.090 & 0.019 & 0.426 & 0.002 \\
\hline Medical emergency & 0.219 & 0.043 & 1.119 & 0.068 & 0.083 & 0.016 & 0.444 & 0.004 \\
\hline Health & 0.125 & 0.020 & 0.782 & 0.026 & 0.083 & 0.013 & 0.530 & 0.009 \\
\hline \multicolumn{9}{|c|}{ Year of entry to the university } \\
\hline 2007 & Reference category & - & - & - & Reference category & - & - & - \\
\hline 2011 & 1.957 & 0.663 & 5.771 & 0.224 & 1.174 & 0.371 & 3.712 & 0.785 \\
\hline 2010 & 1.800 & 0.614 & 5.277 & 0.284 & 1.183 & 0.379 & 3.693 & 0.773 \\
\hline 2009 & 1.125 & 0.060 & 21.087 & 0.937 & 5.143 & 0.465 & 56.897 & 0.182 \\
\hline 2008 & 0.563 & 0.122 & 2.603 & 0.462 & 0.321 & 0.051 & 2.019 & 0.226 \\
\hline
\end{tabular}

OR: odds ratio. In these analyses, mild level anxiety is considered as a reference category.

Table 3. Results of multi-variable analyses for studying relationship between on question variables and test anxiety.

\begin{tabular}{|c|c|c|c|c|c|c|c|c|}
\hline \multirow{3}{*}{ Variables } & \multicolumn{4}{|c|}{ Moderate levels of anxiety compared with the mild } & \multicolumn{4}{|c|}{ High levels of anxiety compared with the mild } \\
\hline & \multirow{2}{*}{ OR } & \multicolumn{2}{|c|}{ 95\% confidence interval OR } & \multirow{2}{*}{ p-Value } & \multirow{2}{*}{ OR } & \multicolumn{2}{|c|}{ 95\% confidence interval OR } & \multirow{2}{*}{ p-Value } \\
\hline & & Low level & High level & & & Low level & High level & \\
\hline \multicolumn{9}{|l|}{ City } \\
\hline Tabriz & 1 & - & - & - & 1 & - & - & - \\
\hline Maragheh & 0.316 & 0.080 & 1.250 & 0.101 & 0.178 & 0.037 & 0.864 & 0.032 \\
\hline Mean of past semesters average & 0.745 & 0.509 & 1.092 & 0.132 & 0.471 & 0.298 & 0.745 & 0.001 \\
\hline \multicolumn{9}{|l|}{ Course of study } \\
\hline Midwifery & 1 & - & - & - & 1 & - & - & - \\
\hline Nursing & 0.381 & 0.034 & 4.261 & 0.433 & 0.231 & 0.019 & 2.856 & 0.254 \\
\hline Medical emergency & 0.285 & 0.021 & 3.833 & 0.344 & 0.222 & 0.014 & 3.589 & 0.289 \\
\hline
\end{tabular}

OR: odds ratio. In these analyses, mild level anxiety is considered as a reference category. Health course is omitted by software because of lack of samples. 
purpose of this study was relationship between test anxiety and academic performance in nursing and midwifery students in Maragheh and Tabriz cities (west of Iran).

Sarason argues that test anxiety is a major devastating factor for all academic performance from the elementary level to the university level.

According Sarason questionnaire, if test anxiety score is more than 15, it shows that the students burden test anxiety. Based on research findings, 69/5\% of students had moderate to severe test anxiety. Average of test anxiety was $15 / 65$; therefore $60 / 5 \%$ of students has test anxiety [6]. Test anxiety score obtained from this study in compared with the study of Moaddeli et al. [16] is high.

Also in a study performed by Clark and colleagues [17], the majority of students had a high level of test anxiety that is consistent with the results of this study [17]. Test findings of this study showed an inverse relationship between test anxiety and academic performance. So that one score increases in average had $53 \%$ less chance for having severe test anxiety (compared with the level of mild anxiety). This finding is in line with the results of some studies in this field [18]-[20], but is inconsistent with results of Bahman Chraghyan and colleagues [21].

This study was performed in the of nursing and midwifery faculty of Tabriz University of Medical Sciences in Tabriz and Maragheh cities. In case of selecting other faculties obtained results of this study can be generalized all of the students of Tabriz University. Or even with wide selection of students, the results can be generalized to the whole of East Azarbaijan students (west of Iran), which it needs conducting the research in a broader level and recommended this subject is flowed by university.

Another limitation of this study was the lack of the samples of participants for the health course which excluded by multivariable analysis. For solving this problem recommended selection of the appropriate number of individuals through sampling with proportional allocation in future studies.

\section{Conclusions}

In this study, city of study (Tabriz compared Maragheh) and student's score variables were obtained as independents foresight in Sarason test anxiety and in a one-variable analysis, the course of study showed a significant relationship with this outcome.

Considering the obtained results, this recommended that using consulting methods, introducing appropriate strategies in study, creating a friendly relationship between professors and students, and conducting interventional studies and educational programs (including educational pamphlets or booklets) can reduce test anxiety level of students.

As test anxiety has negative effects on students' academic performance, identifying its causes and then planning solving those causes are recommended.

\section{Acknowledgements}

We thank all students who participated in this study with their satisfaction. Also we thank from our colleagues in nursing and midwifery faculty of Maragheh and Tabriz for their cooperation in collecting data.

\section{References}

[1] Spielberger, D. and Vagg, P.R. (1995) Test Anxiety: Theory, Assessment and Treatment. Taylor \& Francis, Washington DC.

[2] Sandra, M. (2004) Test Anxiety in Students. http://www.allbusiness.com/health-care-social-assistance/847576-1.html

[3] Berk, R.A. and Nanda, J. (2006) A Randomized Trial of Humor Effects on Test Anxiety and Test Performance. International Journal of Human Research, 19, 425-454.

[4] Ergene, T. (2002) Effective Intervention of Test Anxiety Reduction. School Psychology, 4, 313-328.

[5] Sargolzaie, M.R., Samari, A.A. and Keikhayi, A.A. (2003) Behavioral Methodology and Nervous Oral Planning in Controlling of Test Anxiety. Journal of Mental Health Principals, 5, 34-48.

[6] Sarason, I.G. (1975) Anxiety and Self-Preoccupation: In: Sarason, I.G. and Spielberger, C.D., Eds., Stress and Anxiety, Vol. 2, Hemisphere/Hastead, New York.

[7] Hembree, R. (1988) Correlates, Causes and Treatment of Test Anxiety. Review of Educational Research, 58, 47-77. 
http://dx.doi.org/10.3102/00346543058001047

[8] Liu, J.T., Meng, X.P. and Xu, Q.Z. (2006) The Relationship between Test Anxiety and Personality, Self-Esteem in Grade One Senior High Students. Chinese Journal of Preventive Medicine, 40, 50-52. (Abstract, Article in Chinese)

[9] Narimani, M., Eslam Doust, S. and Ghaffari, M. (2006) The Reasons for Test Anxiety in Students and Solutions to Deal with. Journal of Research and Planning in High Education, 39, 23-40.

[10] Farooqi, Y.N., Ghani, R. and Spielberger, C.D. (2012) Gender Differences in Test Anxiety and Academic Performance of Medical Students. International Journal of Psychology and Behavioral Sciences, 2, 38-43. http://dx.doi.org/10.5923/j.ijpbs.20120202.06

[11] Mac Donald, S.A. (2001) The Prevalence and Effects of Test Anxiety in School Children. Educational Psychology, 21, 89-101.

[12] Khosravi, M. and Bgdeli, I. (2008) The Relationship between Personality Factors and Test Anxiety among University Students. Journal of Behavioral Sciences, 2, 13-24.

[13] Hembree, R. (1988) Correlates, Causes and Treatment of Test Anxiety. Review of Educational Research, 58, 47-77. http://dx.doi.org/10.3102/00346543058001047

[14] Rezazadeh, M. and Tavakoli, M. (2009) Investigating the Relationship among Test Anxiety, Gender, Academic Achievement and Years of Study: A Case of Iranian EFL University Students. English Language Teaching, 2, 68. http://dx.doi.org/10.5539/elt.v2n4p68

[15] Chapell, M.S., Blanding, Z.B., Silverstein, M.E., Takahashi, M., Newman, B., Gubi, A. and McCann, N. (2005) Test Anxiety and Academic Performance in Undergraduate and Graduate Students. Journal of Educational Psychology, 97, 268-274. http://dx.doi.org/10.1037/0022-0663.97.2.268

[16] Moadeli, Z. and Ghazanfari-Hesamabadi, M. (2005) A Survey on the Students' Exam Anxiety in the Fatemeh (P.B.U.H.) College of Nursing and Midwifery, Spring 2004. Journal of Strides in Development of Medical Education, 1, 65-72.

[17] Clark, J.W., Fox, P.A. and Sheneider, H.G. (1998) Feedback, Test Anxiety and Performance in a College Course. Psychological Reports, 82, 203-208. http://dx.doi.org/10.2466/pr0.1998.82.1.203

[18] Cassady, J.C. (2004) The Influence of Cognitive Test Anxiety across the Learning-Testing Cycle. Learning and Instruction, 14, 569-592. http://dx.doi.org/10.1016/j.learninstruc.2004.09.002

[19] Hong, E. and Karstensson, L. (2002) Antecedents of State Test Anxiety. Contemporary Educational Psychology, 27, 348-367. http://dx.doi.org/10.1006/ceps.2001.1095

[20] Abollghasemi, A. and Nadjarian, B. (1999) Test Anxiety Assessment and Treatment. Journal of Psychological Researches, 5, 82-97.

[21] Cheraghian, B., Fereidooni-Moghadam, M., Baraz-Pardejani, S.H. and Bavarsad, N. (2008) Test Anxiety and Its Relationship with Academic Performance among Nursing Students. Knowledge \& Health, 3, 25-29. 
Scientific Research Publishing (SCIRP) is one of the largest Open Access journal publishers. It is currently publishing more than 200 open access, online, peer-reviewed journals covering a wide range of academic disciplines. SCIRP serves the worldwide academic communities and contributes to the progress and application of science with its publication.

Other selected journals from SCIRP are listed as below. Submit your manuscript to us via either submit@scirp.org or Online Submission Portal.
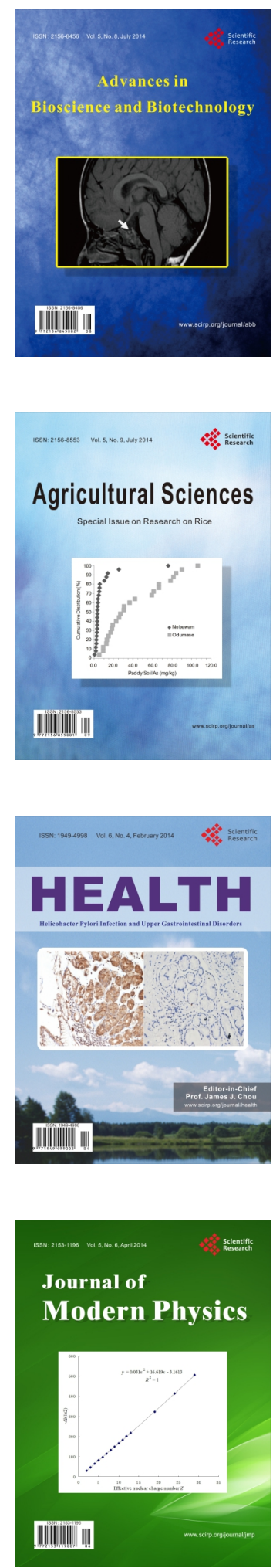
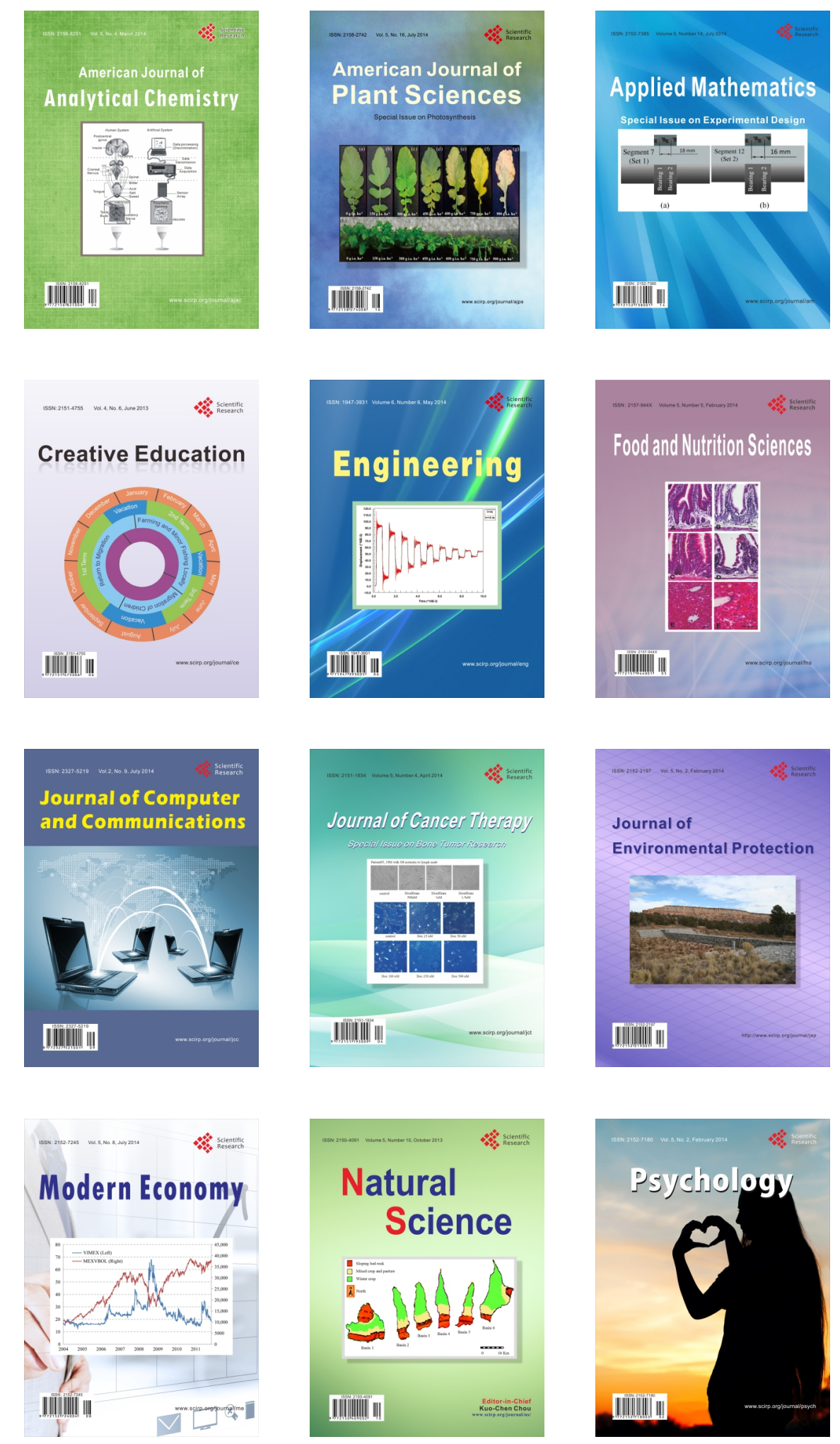